\title{
PALIMPSESTO
}

PALIMPSESTOS

1031 Bohigas inédito I Lluís Clotet, Enrique Granell, Juan José Lahuerta, Antoni Llena ।

107ı Cátedra Blanca. Diez perfiles I Francisco González de Canales, Cecilia Obiol, Estel Ortega, Eva Prats, Anna Puigjaner, Stel.lla Rahola, Pau Sarquella, Ivan Shumkov, Jorge Vidal, Xavier Vilalta I

1171 Veinte años de Cátedra Blanca

1181 Conversación I Olga Felip, Eduard Gascón, Ramon Godó, Judith Leclerc, Julio Mejón, Mara Partida I

I201 Contra. El ejercicio del banco I Federico Correa I

4 EUR

Otoño 2019

\section{Bohigas inédito}

En esta efeméride substituimos la palabra por el dibujo por cinco de ellos, surgidos de manera informal de una de las manos más cultas e inquietas que ha dado la arquitectura y el pensamiento del siglo XX en Cataluña; la de Oriol Bohigas. La selección de estos esbozos realizada junto a Beth Galí, habla de una producción inédita, sin encargo ni formato que radiografía sus anhelos de arquitecto y dibujante reivindicando esta condición por delante de la del glosado intelectual y gestor cultural.

Miremos qué ha dibujado Oriol Bohigas casi sin querer, y reflexionemos sobre ello no solo para entender al arquitecto, sino también un período y una manera de ver el mundo desde la disciplina. Los intérpretes de estos trazos de flâneur de la arquitectura son Lluís Clotet, Enric Granell, Juan José Lahuerta y Antoni Llena, aportando cuatro lúcidas visiones casi a bote pronto que dialogan entre sí sin saberlo y alumbran de un fogonazo un período fundacional que construyó la Escuela de Barcelona, tanto la profesional como la académica.

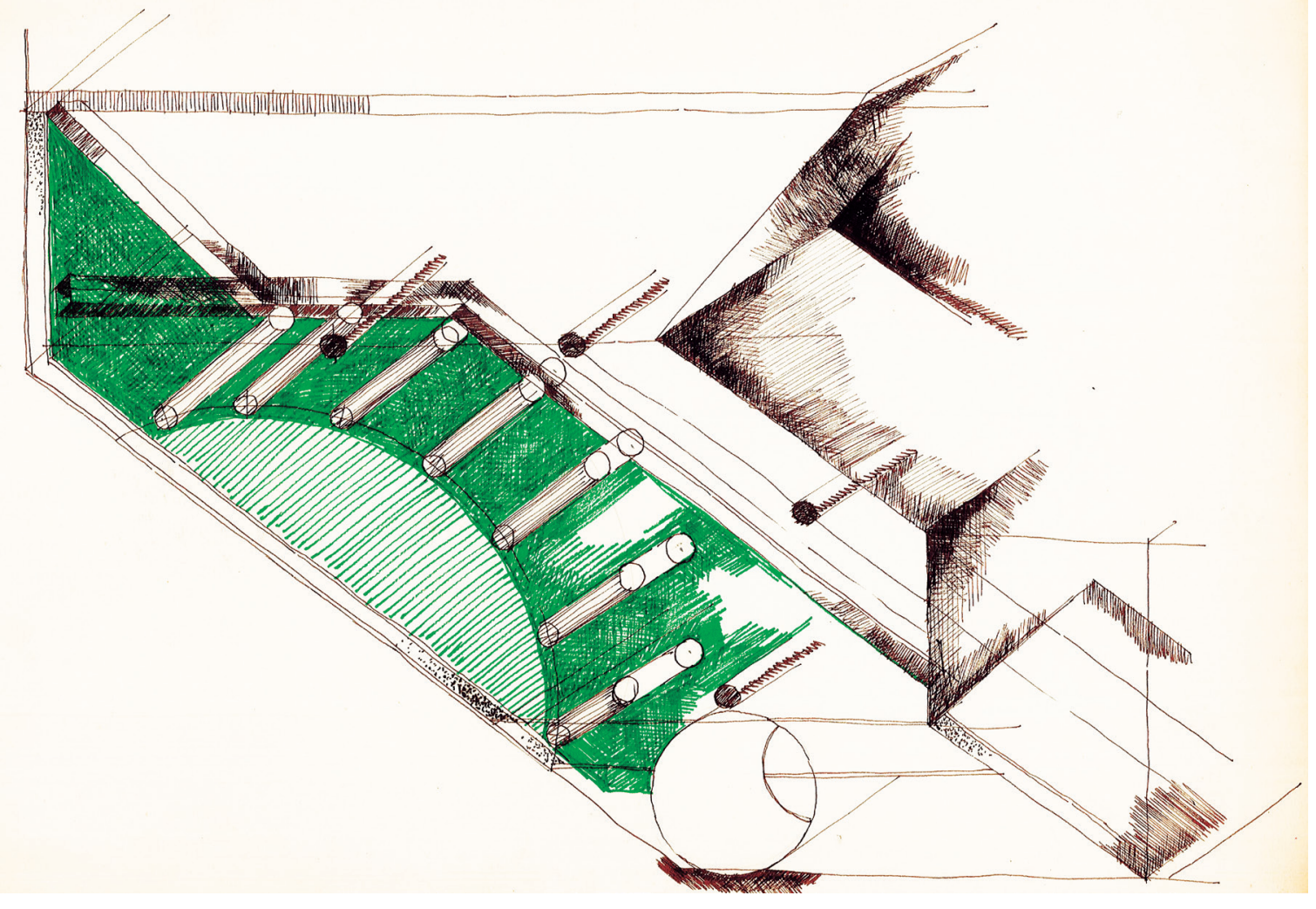

\section{Cátedra Blanca. Diez perfiles}

Alumnos y profesores de la Cátedra Blanca de los últimos 20 años

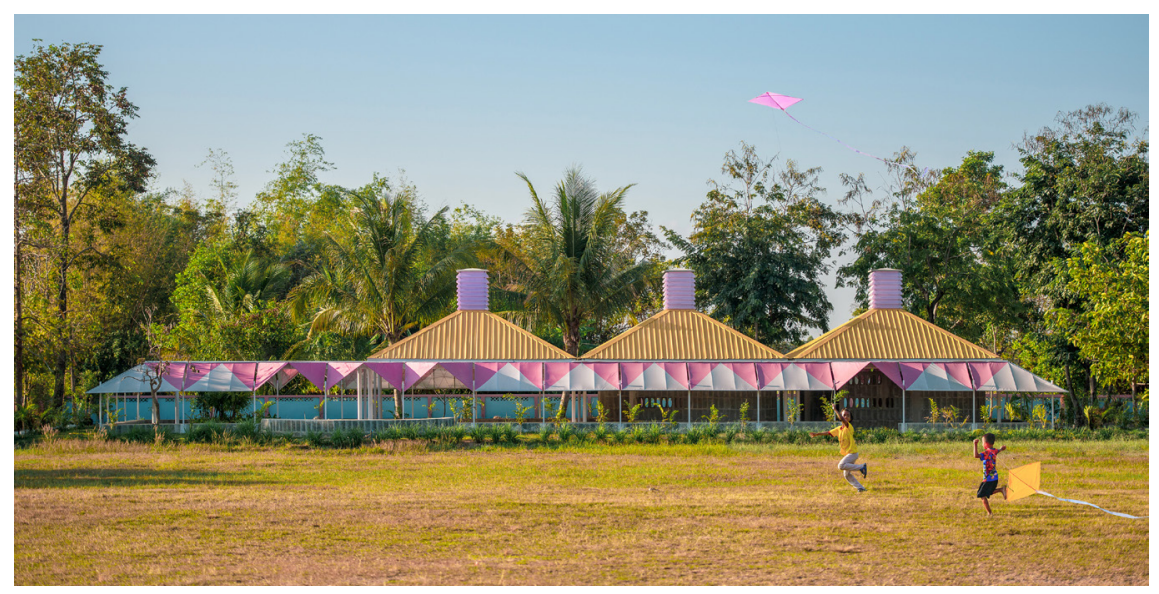

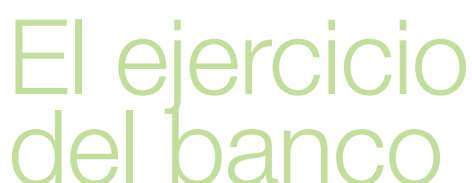

Federico Correa

El dibujo substituye también aquí a la palabra en el célebre ejercicio del banco de Federico Correa, sinécdoque de la docencia de la arquitectura. La tarea asignada a los estudiantes de primer curso marcó a muchas generaciones en la ETSAB y da cuenta de un modelo de Escuela que la Cátedra ha cultivado y renovado durante estos veinte años. El banco (el proyecto) como dibujo, representa de nuevo el equilibro entre el pensamiento culto y la acción sensible que ilustramos aquí con las propuestas de Ignasi de Solà-Morales, Manel Brullet y Albert Viaplana rescatadas de los archivos de la Biblioteca de la Escuela.

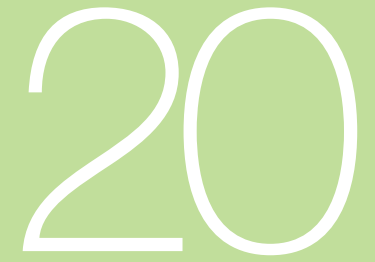

